\title{
Pathogenicity of Streptomyces scabies Mutants Altered in Thaxtomin A Production
}

\author{
Claudia Goyer, Joanne Vachon, and Carole Beaulieu
}

Groupe de Recherche en Biologie des Actinomycètes, Département de Biologie, Université de Sherbrooke, Sherbrooke, Québec, Canada, J1K 2R1. Accepted for publication 23 January 1998.

\begin{abstract}
Goyer, C., Vachon, J., and Beaulieu, C. 1998. Pathogenicity of Streptomyces scabies mutants altered in thaxtomin A production. Phytopathology 88:442-445.

To investigate the role of thaxtomin A in the pathogenicity of Streptomyces scabies, mutants altered in thaxtomin A production were obtained by $N$-methyl- $N^{\prime}$-nitro- $N$-nitrosoguanidine mutagenesis. Mutants of $S$. scabies EF-35 could be differentiated according to levels of thaxtomin production. Mutants M1, M8, and M19 produced 2 to 20 times less thax-

tomin A in oat bran medium than did EF-35. M1 and M19 were deficient in tryptophan catabolism. Thaxtomin production was reduced by about 300 times in mutant M16, which was a glutamic acid auxotroph. No thaxtomin A was detected in M13 culture supernatant. This mutant had a normal growth rate, was prototrophic, and catabolized tryptophan. Pathogenicity of mutants was tested on radish and potato. Mutants M1, M8, and M19 were pathogenic but, in most cases, less virulent than EF-35. M13 and M16 were nonpathogenic. These results suggest that thaxtomin A is an important pathogenicity determinant in S. scabies.
\end{abstract}

Phytotoxins are produced by several plant-pathogenic bacteria, such as Pseudomonas tolaasii (3), P. syringae pv. syringae (31), $P$. syringae pv. phaseolicola (28), P. syringae pv. tagetis $(22,25)$, and $P$. syringae pv. glycinae (27). These compounds elicit a variety of symptoms including wilting, chlorosis, necrosis, water-soaking, and growth abnormalities. In 1989, a new group of phytotoxins associated with plant-pathogenic streptomycetes was discovered (16) and called thaxtomin. Thaxtomins consist of 4-nitroindol-3-ylcontaining 2,5-dioxopiperazines, and they were first isolated from common scab lesions induced by Streptomyces scabies on potato (Solanum tuberosum L.) tissues. Thaxtomin A, the major phytotoxin produced by $S$. scabies, is composed of two modified $\mathrm{N}$ methylated amino acids, $\alpha$-hydroxy- $m$-tyrosine plus 4-nitro-tryptophan $(15,18)$. Thaxtomin A is produced by $S$. scabies on potato tissues and also in some culture media containing plant extracts such as oatmeal broth (1) or potato peel broth (8). Thaxtomins are not produced in minimal or rich media without plant extracts (20).

Evidence for a crucial role of thaxtomin A in pathogenesis continues to accumulate (10,17-20). Application of purified thaxtomin A on potato mini-tubers causes necrosis of treated tissues (18). Thaxtomin A also inhibits growth of seedlings such as radish ( $R a-$ phanus sativus L.), alfalfa (Medicago sativa L.), cauliflower (Brassica oleracea L.), colza (Brassica napus L.), and turnip (Brassica rapa L.) (19). Plant tissues treated with thaxtomin A show thickening of their cell walls and hypertrophy (19). Furthermore, King et al. (17) established a positive correlation between pathogenicity of $S$. scabies and thaxtomin production. Loria et al. (20) also suggested that symptom severity on potato tubers correlates with the amount of thaxtomin A produced by different potato scab-inducing streptomycetes. Healy et al. (10) recently showed that mutants of $S$. scabies defective in thaxtomin A production are nonpathogenic on radish seedlings.

Thaxtomin biosynthesis is not limited to S. scabies; other streptomycetes causing potato scab such as $S$. acidiscabies (17) and $S$. caviscabies (8), as well as the causal agent of soil rot of sweet pota-

Corresponding author: C. Beaulieu; E: mail address: c.beauli@courrier.usherb.ca

Publication no. P-1998-0316-02R

(C) 1998 The American Phytopathological Society to, $S$. ipomoeae (12), produce thaxtomin. Thaxtomin production thus appears as a common feature of plant-pathogenic streptomycetes.

In this work, the involvement of thaxtomin A in the pathogenicity of $S$. scabies strain EF-35 was analyzed. EF-35 was isolated in Québec, Canada, from a scab lesion on a potato tuber (5). This strain causes common scab not only on potato, but also on carrot, sugar beet, turnip, parsnip, and radish (7). EF-35 produces an average of $2.2 \mu \mathrm{g}$ of thaxtomin A per $1 \mathrm{mg}$ of cells (dry weight) in oat bran broth. Following $N$-methyl- $N$-nitro- $N$-nitrosoguanidine (NTG) mutagenesis, mutants of $S$. scabies EF-35 altered in thaxtomin A production were obtained and briefly characterized, and their pathogenic behavior was analyzed on both radish seedlings and potato tubers.

\section{MATERIALS AND METHODS}

Chemical mutagenesis and selection of mutants altered in thaxtomin A production. NTG mutagenesis was carried out on spores of S. scabies EF-35 (7) as described by Hopwood et al. (11). Following mutagenesis, $S$. scabies spores were diluted, plated on yeast malt extract agar (29), and grown for 5 days at $30^{\circ} \mathrm{C}$. Developing colonies were transferred to oat bran agar for detection of thaxtomin production. Oat bran agar was prepared by boiling $40 \mathrm{~g}$ of oat bran per 1 liter of water for $15 \mathrm{~min}$. Insoluble matter was removed by centrifuging $15 \mathrm{~min}$ at $10,000 \times \mathrm{g}$. Supernatant was kept and $2 \%$ agar was added. After 6 days of incubation at $30^{\circ} \mathrm{C}$, production of thaxtomin was detected by the presence of a yellowish halo surrounding the colonies, and recorded. Colonies with no detectable halo were restreaked twice on fresh oat bran agar.

Production and purification of thaxtomin A. Overnight cultures of $S$. scabies EF-35 and of mutants, grown with shaking (300 $\mathrm{rpm}$ ) at $30^{\circ} \mathrm{C}$ in $25 \mathrm{ml}$ of tryptic soy broth (TSB) (Difco Laboratories, Detroit), were centrifuged in graduated tubes. The volume of each pellet was measured, and these were then diluted in five volumes of fresh TSB. An aliquot of $80 \mu$ l of each fresh cell suspension was used to inoculate $25 \mathrm{ml}$ of oat bran broth, and the cultures were incubated with shaking $(300 \mathrm{rpm})$ at $30^{\circ} \mathrm{C}$ for 8 days. After centrifugation of the bacterial cultures, the pellets were dried overnight in an oven at $80^{\circ} \mathrm{C}$ and weighed; thaxtomin A was extracted from supernatants using an equal volume of ethyl acetate. The ethyl acetate phase containing thaxtomin A was concentrated 
on a Büchi Rotavapor R-114 (Büchi Labortechnik AG, Flawil, Switzerland). The resulting material was redissolved in ethyl acetate and separated by thin-layer chromatography on glass plates precoated with $0.25 \mathrm{~mm}$ of silica gel 60 , using chloroform/methanol (9:1) as migration solvents. Yellow products with an $R_{f}$ of 0.27 (thaxtomin A) were eluted from the silica gel using chloroform/ methanol (7:3). Thaxtomin extraction experiments were carried out on three different cultures for each strain.

Quantification of thaxtomin A. The level of thaxtomin A production between the wild-type strain and the selected mutants was compared using a sensitive test as described below. Thaxtomin A was quantified by high-performance liquid chromatography (HPLC) using a Varian LC5500 liquid chromatograph (Varian Chromatography Systems, Walnut Creek, CA) equipped with a Water's C18 column (10- $\mu \mathrm{m}$ particle size, $3.9 \mathrm{~mm} \times 125 \mathrm{~mm}$; Waters Corporation, Milford, MA). Thaxtomin A was eluted from the column with a 25 to $50 \%$ acetonitrile gradient for $20 \mathrm{~min}$ at a flow rate of 1.3 $\mathrm{ml} / \mathrm{min}$ and monitored at $249 \mathrm{~nm}$ using a UV detector. UV spectroscopic analyses were performed with an LKB spectrophotometer (model Ultrospec III; LKB Biochrom, Cambridge) using the extinction coefficient of thaxtomin A (249 nm, ع15070) determined by King et al. (15). A standard curve was established using dilutions of a known quantity of purified thaxtomin A.

Characterization of mutants. The ability of each mutant to sporulate was tested by spreading $1 \mathrm{ml}$ of a 3-day-old TSB culture of the mutant or the wild-type strain EF-35 onto SLM3 agar (10 g of starch, $5 \mathrm{ml}$ of corn steep liquor [Sigma Chemical Co., St. Louis], $3 \mathrm{~g}$ of $\mathrm{CaCO}_{3}, 12 \mathrm{mg}$ of $\mathrm{Fe}_{2} \mathrm{SO}_{4}$, and $20 \mathrm{~g}$ of agar per liter). The presence of spores was recorded after incubation for 7 days at $30^{\circ} \mathrm{C}$.

Minimal medium, used to test bacterial growth, consisted of $10 \mathrm{~g}$ of glucose, $12 \mathrm{~g}$ of agar, $0.5 \mathrm{~g}$ of $\mathrm{K}_{2} \mathrm{HPO}_{4}, 0.2 \mathrm{~g}$ of $\mathrm{MgSO}_{4}$, and $0.01 \mathrm{~g}$ of $\mathrm{FeSO}_{4}$ per 1 liter of water (10). Amino acids or $\left(\mathrm{NH}_{4}\right)_{2} \mathrm{SO}_{4}$ were used as a nitrogen source and were added to minimal medium at a final concentration of 0.1 and $0.2 \%$, respectively. Growth on minimal media was observed after incubation for 7 days at $30^{\circ} \mathrm{C}$.

To compare the growth rate, cell suspensions of each mutant and wild-type strain EF-35 were adjusted to the same concentration and were used to inoculate three flasks containing $300 \mathrm{ml}$ of TSB. Bacteria were grown with shaking $(300 \mathrm{rpm})$ at $30^{\circ} \mathrm{C}$ for $45 \mathrm{~h}$. At intervals, $10-\mathrm{ml}$ aliquots of the cultures were removed and centrifuged to determine the dry mass of mycelium as described above.

Pathogenicity tests. Pathogenicity of $S$. scabies EF-35 and of mutants was tested on Solanum tuberosum cv. Kennebec according to Faucher et al. (5). Potato tubers were harvested after 8 weeks and examined for common scab symptoms. The number of tubers presenting symptoms was recorded. The coverage of common scab lesions on each infected tuber was estimated visually.

Pathogenicity tests were also carried out on radish seedlings as described by Leiner et al. (19) with the following modifications. Seeds of radish cv. Cherry Belle were sterilized 5 min with $0.26 \%$
$\mathrm{NaOCl}$ and were then rinsed twice with sterile water. The seeds were then germinated in the dark for $24 \mathrm{~h}$ in petri dishes containing $15 \mathrm{~g}$ of agar per 1 liter of water. Individual seedlings were transferred to the top of an agar slant (1.5\%) in 50-ml tubes. Bacterial inocula used to infect radish seedlings were prepared as follows: bacteria were grown with shaking $(300 \mathrm{rpm})$ in TSB for 2 days at $30^{\circ} \mathrm{C}$. Cultures were centrifuged in graduated tubes, and the volume of the pellets was measured. Bacterial mycelia were resuspended in a volume of fresh TSB equivalent to five volumes of pellet, and these cell suspensions were used as inocula. An inoculum $(200 \mu \mathrm{l})$ of $S$. scabies wild-type strain EF-35 or of each mutant was applied to radish seedlings, whereas $200 \mu \mathrm{l}$ of sterile TSB was added to control seedlings. These seedlings were incubated in a growth chamber at $23^{\circ} \mathrm{C}$ on a 16 -h photoperiod. Seedlings were grown under Gro Lux wide-spectrum fluorescent lighting (General Electric, Cleveland) with a quantum flux density of $175 \mu \mathrm{E} \mathrm{m}^{-2} \mathrm{~s}^{-1}$. After incubation for 6 days, radish seedlings were removed from the tubes and their lengths measured. The difference between the length of uninoculated controls and treated seedlings was divided by the length of controls to evaluate growth inhibition.

A single pathogenicity test comprised five replicates. All pathogenicity tests experiments were repeated three times.

\section{RESULTS}

Chemical mutagenesis and selection of mutants altered in thaxtomin A production. Six thousand colonies of S. scabies strain EF-35 were recovered from the NTG mutagenesis, and about $1.5 \%$ of them were auxotrophic mutants. These 6,000 colonies were screened for thaxtomin production on oat bran agar. Thaxtomins are yellow compounds (15). Production of thaxtomin by S. scabies on oat bran agar can be detected by the presence of a yellowish halo surrounding colonies. Five mutants (M1, M8, M13, M16, and M19) produced no detectable yellowish halo on oat bran agar. Selected mutants were then compared with the wild-type strain EF-35 for thaxtomin production in oat bran broth. The wild-type strain produced approximately 2,240 $\mathrm{ng}$ of thaxtomin A per $1 \mathrm{mg}$ of dried cells after incubation for 8 days in oat bran broth. Mutants were differentiated according to level of thaxtomin A production. Mutants M1, M8, and M19 produced 2 to 20 times less thaxtomin A than did the wild-type strain EF-35. Thaxtomin A production for mutants M1, M8, and M19 ranged from 227 to $1045 \mathrm{ng} / \mathrm{mg}$ (Table 1).

M16 produced 355 times less thaxtomin A than did the wildtype strain EF-35. A small amount of thaxtomin A $(6.3 \mathrm{ng} / \mathrm{mg})$ was recovered in the supernatant of mutant M16 after incubation for 8 days (Table 1). M13 was the only mutant producing no detectable amount of thaxtomin A after incubation for 8 days in oat bran broth (Table 1).

Characterization of mutants. As did the wild-type strain, all mutants except M16 grew on minimal medium containing an in-

TABLE 1. Pathogenicity on radish seedlings and on potato tubers of Streptomyces scabies and of mutants altered in thaxtomin A production

\begin{tabular}{|c|c|c|c|c|}
\hline \multirow[b]{3}{*}{ Strain or treatment } & \multirow{3}{*}{$\begin{array}{c}\text { Amount of thaxtomin A } \\
\text { (ng/mg of dried mycelium) }^{\mathrm{w}}\end{array}$} & \multicolumn{2}{|c|}{ Pathogenicity on ${ }^{\mathrm{x}}$} & \multirow[b]{3}{*}{ Surface of infected tubers covered by lesions $(\%)$} \\
\hline & & Radish seedlings & Potato tubers & \\
\hline & & $\overline{\text { Growth inhibition }(\%)}$ & Infected potato tubers $(\%)$ & \\
\hline EF-35 & $2239.2 \mathrm{a}^{\mathrm{y}}$ & $72 \mathrm{a}^{\mathrm{y}}$ & $76 a^{z}$ & $20 \mathrm{a}^{\mathrm{z}}$ \\
\hline M8 & $1045.4 \mathrm{~b}$ & $42 \mathrm{bc}$ & $22 \mathrm{c}$ & $4 \mathrm{bc}$ \\
\hline M19 & $309.5 \mathrm{c}$ & $42 \mathrm{bc}$ & $37 \mathrm{bc}$ & $4 \mathrm{bc}$ \\
\hline M1 & $227.3 \mathrm{c}$ & $59 \mathrm{ab}$ & $54 \mathrm{ab}$ & $9 \mathrm{~b}$ \\
\hline M16 & $6.3 \mathrm{~d}$ & $26 \mathrm{~cd}$ & $0 \mathrm{~d}$ & $0 \mathrm{c}$ \\
\hline M13 & $0.0 \mathrm{~d}$ & $27 \mathrm{~cd}$ & $0 \mathrm{~d}$ & $0 \mathrm{c}$ \\
\hline Noninoculated medium & $0.0 \mathrm{~d}$ & $0.0 \mathrm{~d}$ & $0 \mathrm{~d}$ & $0 \mathrm{c}$ \\
\hline
\end{tabular}

${ }^{\mathrm{w}}$ Amount of thaxtomin A produced in oat bran broth. Results are the mean of three replications.

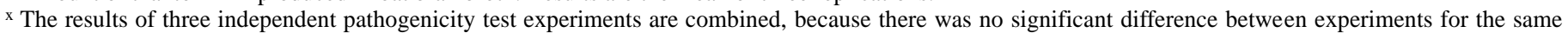
treatment variable $(P<0.05)$. A single experiment comprised five replicates.

y Numbers accompanied by the same letters are not significantly different $(P<0.05, t$ test $)$.

${ }^{\mathrm{z}}$ Numbers accompanied by the same letters are not significantly different $\left(P<0.05\right.$, series of $2 \times 2 \chi^{2}$ test $)$. 
organic nitrogen source (Table 2). Mutant M16 did not grow on a minimal medium containing $\left(\mathrm{NH}_{4}\right)_{2} \mathrm{SO}_{4}$ as the sole nitrogen source. However, the growth of this auxotrophic mutant was restored when glutamic acid was supplied to minimal medium (Table 2). Glutamine also restored growth of M16 on minimal medium, but the growth remained poor compared with that of the wild-type strain. Although M1 and M19 could grow on minimal medium containing $\left(\mathrm{NH}_{4}\right)_{2} \mathrm{SO}_{4}$, these mutants did not grow on minimal media when tryptophan was used as the sole nitrogen source (Table 2). By contrast, they could utilize other amino acids such as L-alanine, Lglutamic acid, L-phenylalanine, L-serine, and L-tyrosine (Table 2).

Growth curves in TSB were similar for wild-type strain EF-35 and for all mutants (data not shown). All mutants except M16 sporulated on SLM3 (Table 2). However, addition of $0.1 \%$ L-glutamic acid to SLM3 restored the ability to sporulate in M16.

Pathogenicity tests on radish seedlings. Radish seedlings inoculated with mutants M1, M8, and M19 or with wild-type strain EF-35 showed growth inhibition ranging from 42 to $72 \%$ when compared with that of noninoculated controls. EF-35 and M1 were the most virulent strains, causing 72 and $59 \%$ growth inhibition, respectively. M8 and M19 were less virulent than EF-35 on radish seedlings. Indeed, radish seedlings inoculated with mutants M8 and M19 were significantly taller than those inoculated with the wild-type strain, yet they remained shorter than the noninoculated controls. Even though mutants M13 and M16 inhibited growth by 27 and 26\%, respectively, the differences in lengths between noninoculated and inoculated seedlings was not significantly different for these two mutants (Table 1).

Pathogenicity tests on potato tubers. S. scabies strain EF-35 induced common scab on $76 \%$ of the progeny tubers, and the lesions covered an average of $20 \%$ of the tuber surface (Table 1). Mutant M1 caused common scab symptoms on only $54 \%$ of the progeny tubers; however, the difference in infection incidence between EF-35 and M1 was not significantly different $(P<0.05)$. Nevertheless, M1 was shown to be significantly less virulent than the wild-type strain; an average of only $9 \%$ of the tuber surface was covered by scab lesions for M1 as compared with $20 \%$ for EF-35 (Table 1). M19 and M8 were also significantly less virulent than the wild-type strain; the percentage of infected tubers and the coverage of scab lesions being reduced by factors of 2.0 to 3.5 and of 5.0, respectively (Table 1). Mutants M13 and M16, which showed the greatest reduction in thaxtomin A production, were nonpathogenic on potato (Table 1).

\section{DISCUSSION}

Studies have suggested that thaxtomin A acts as an important pathogenicity determinant in plant-pathogenic Streptomyces spp. (17-20). To further investigate the role of thaxtomin A in pathogenicity, we analyzed the pathogenic behavior of S. scabies mutants altered in thaxtomin A production. Mutants were selected for the absence of a yellowish halo around colonies growing on oat bran agar. Most of the selected mutants still produced thaxtomin A, even though no yellowish halo was detected on oat bran agar. Opacity of the oat bran medium probably prevents the detection of faint halos. Nevertheless, oat bran agar appears to be a good screening medium, because all selected mutants were severely reduced in thaxtomin A production and because melanoid pigments (9) that could mask thaxtomins were not produced by $S$. scabies in oat bran medium.

Mutants producing up to 20 times less thaxtomin A than the wild-type strain were all pathogenic on potato, as well as on radish seedlings. In these mutants, reduction in thaxtomin A biosynthesis coincided with a reduced virulence on potato. For mutants M8 and M19, the decrease in the amount of thaxtomin A produced in oat bran broth also coincided with reduced virulence on radish seedlings. Radish seedlings thus appear to be a useful tool to screen for pathogenic $S$. scabies. This system could be considered a useful alternative to using potato tubers to screen for plant-pathogenic streptomycetes, especially because testing pathogenicity on potato is time-consuming and requires important greenhouse or growth chamber space.

No strict correlation was found between virulence and thaxtomin A production. For example, M8 produced about three times more thaxtomin A than did M1 and M19, but was less virulent on plants. However, thaxtomin production in oat bran broth might not necessarily reflect the in planta production of thaxtomin on potato tubers or radish seedlings. In a previous study, Loria et al. (20) suggested that differential virulence of two $S$. scabies strains reflected the level of thaxtomin A production in oatmeal broth. However, strains analyzed in the study of Loria et al. (20) did not share the same genetic background. Consequently, the possibility that differential virulence is due to pathogenicity determinants other than thaxtomin A should not be excluded. Other factors, such as phytohormones (21) and hydrolytic enzymes (4,23), might also be involved in the disease process.

Mutants M16 and M13 were the most severely affected in thaxtomin A production. Mutant M16 produced 355 times less thaxtomin A than did the wild-type strain EF-35 and thaxtomin production could not be detected in mutant M13. These mutants were nonpathogenic on both potato tubers and radish seedlings. This confirms the work of Healy et al. (10), who previously showed that mutants defective in thaxtomin A were nonpathogenic. In contrast to other phytotoxins, such as coronatin $(2,26)$ and tabtoxin $(33)$, which contribute to symptom development but are not essential to pathogenicity, thaxtomin A seems to play an essential role in pathogenicity.

The biosynthetic pathway of thaxtomin A has not been elucidated yet. However, King and Lawrence $(13,14)$ suggested that precursors of the biosynthesis are phenylalanine and 4-nitro-tryptophan. The phenotype of mutants M1 and M19, both deficient in tryptophan catabolism, suggests that an enzyme involved in tryptophan catabolism may also be required for thaxtomin A biosynthesis. Other Streptomyces spp. are known to produce secondary metabolites for which a modified tryptophan is a precursor molecule. Actinomycin (32), streptonigrin (30), staurosporine (24), and thiostrepton (6) are examples of such secondary metabolites.

TABLE 2. Characterization of Streptomyces scabies EF-35 and of mutants affected in thaxtomin A production

\begin{tabular}{|c|c|c|c|c|c|c|c|c|c|}
\hline \multirow[b]{2}{*}{ Strain } & \multirow[b]{2}{*}{ Sporulation $^{\mathrm{w}}$} & \multicolumn{8}{|c|}{ Nitrogen sources utilized } \\
\hline & & $\left(\mathrm{NH}_{4}\right)_{2} \mathrm{SO}_{4}$ & Alanine & Glutamic acid & Glutamine & Serine & Phenylalanine & Tryptophan & Tyrosine \\
\hline EF-35 & $+^{x}$ & + & + & + & + & + & + & + & + \\
\hline M1 & + & + & + & + & + & + & + & $-\mathrm{y}$ & + \\
\hline M8 & + & + & + & + & + & + & + & + & + \\
\hline M13 & + & + & + & + & + & + & + & + & + \\
\hline M16 & - & - & - & + & $\pm^{\mathrm{z}}$ & - & - & - & - \\
\hline M19 & + & + & + & + & + & + & + & - & + \\
\hline
\end{tabular}

${ }^{\text {w }}$ Sporulation was tested on SLM3 medium.

$\mathrm{x}+$ means that growth or sporulation was recorded.

$\mathrm{y}$ - means that no growth or sporulation was recorded.

$\mathrm{z} \pm$ means that scarce growth was recorded. 
M16 is an auxotrophic mutant and, like other Streptomyces auxotrophic mutants (34), it is affected in its sporulation ability. Addition of glutamic acid to minimal medium and, to a lesser extent, addition of glutamine, restored its ability to grow on minimal medium and to sporulate. Since glutamic acid acts as an $\alpha$-amino group donor in the biosynthesis of several amino acids, it is likely that glutamic acid will influence the synthesis of a product derived from amino acid metabolism, such as thaxtomin A.

Similarly to M8, M13 grew normally, was not auxotrophic, and could catabolize tryptophan. Nevertheless, M13 lost the ability to produce a detectable amount of thaxtomin, suggesting that some of the genes responsible for thaxtomin A biosynthesis are not involved in tryptophan catabolism. The decrease in thaxtomin production for M8 and M13 suggests that the enzyme encoded by the mutated gene was less efficiently produced or somehow impaired.

Given the mutagenesis procedure, it cannot be totally excluded that some mutants could carry multiple mutations that could affect thaxtomin production independently of auxotrophy and loss of pathogenicity. However, mutant phenotypes suggest that amino acid metabolism is closely linked to thaxtomin A biosynthesis. Mutants M1 and M19 appear to carry mutations in genes involved in tryptophan catabolism, while M16 carries a mutation in a gene involved in the biosynthesis of an amino acid. The functions of the mutated genes in M8 and M13 are still unknown, but they may be involved in the regulation of thaxtomin production or in some biochemical step specific to thaxtomin synthesis.

This study represents a first step to localize and analyze the genes of $S$. scabies involved in the biosynthesis of thaxtomins and in the regulation of thaxtomin production. The mutants obtained in this study will be useful tools to study the biochemistry and genetics of thaxtomin biosynthesis.

\section{ACKNOWLEDGMENTS}

This work was supported by a grant from the Natural Sciences and Engineering Research Council of Canada given to C. Beaulieu, and a scholarship from the Fonds pour la Formation des Chercheurs et l'aide à la Recherche du Gouvernement du Québec given to C. Goyer. We thank P. Béchard and A. Gauthier for critical review of the manuscript, and J. W. Shipley for his help with statistical analysis.

\section{LITERATURE CITED}

1. Babcock, M. J., Eckwall, E. C., and Schottel, J. L. 1993. Production and regulation of potato-scab-inducing phytotoxins by Streptomyces scabies. J. Gen. Microbiol. 139:1579-1586.

2. Bender, C. L., Stone, H. E., Sims, J. J., and Cooksey, D. A. 1987. Reduced fitness of Pseudomonas syringae pv. tomato Tn5 mutants defective in coronatine production. Physiol. Mol. Plant Pathol. 30:273-283.

3. Brodey, C., Rainey, P. B., Tester, M., and Johnstone, K. 1991. Bacterial blotch disease of the cultivated mushroom is caused by an ion channel forming lipodepsipeptide toxin. Mol. Plant-Microbe Interact. 4:407-411.

4. Faucher, E., Paradis, E., Goyer, C., Hodge, N. C., Hogue, R., Stall, R. E., and Beaulieu, C. 1995. Characterization of streptomycetes causing deeppitted scab of potato in Québec. Int. J. Syst. Bacteriol. 45:222-225.

5. Faucher, E., Savard, T., and Beaulieu, C. 1992. Characterization of actinomycetes isolated from common scab lesions on potato tubers. Can. J. Plant Pathol. 14:197-202.

6. Frenzel, T., Zhou, P., and Floss, H. G. 1990. Formation of 2-methyltryptophan in the biosynthesis of thiostrepton: Isolation of S-adenosylmethionine: tryptophan 2-methyltransferase. Arch. Biochem. Biophysics. 278:35-40.

7. Goyer, C., and Beaulieu, C.. 1997. Host range of streptomycete strains causing common scab. Plant Dis. 81:901-904.

8. Goyer, C., Otrysko, B., and Beaulieu, C. 1996. Taxonomic studies on streptomycetes causing potato common scab: A review. Can. J. Plant Pathol. 18:107-113.

9. Gregory, K. F., and Vaisey, E. B. 1956. Pathogenicity of tyrosinase-deficient mutants of Streptomyces scabies. Can. J. Microbiol. 2:65-71.
10. Healy, F. G., King, R. R., and Loria, R. 1997. Identification of thaxtomin A non-producing mutants of Streptomyces scabies. (Abstr.) Phytopathology 87:S41.

11. Hopwood, D. A., Bibb, M. J., Chater, K. F., Kieser, T., Bruton, C. J., Kieser, H. M., Lydiate, D. J., Smith, C. P., Ward, J. M., and Schrempf, H. 1985. Genetic Manipulation of Streptomyces: A Laboratory Manual. The John Innes Foundation, Norwich, England.

12. King, R. R., and Lawrence, C. H. 1994. Isolation and characterization of thaxtomin-type phytotoxins associated with Streptomyces ipomoeae. J. Agric. Food Chem. 42:1791-1794.

13. King, R. R., and Lawrence, C. H. 1995. 4-nitrotryptophans associated with the in vitro production of thaxtomin A by Streptomyces scabies. Phytochemistry 40:41-43.

14. King, R. R., and Lawrence, C. H. 1996. Characterization of new thaxtomin A analogues generated in vitro by Streptomyces scabies. J. Agric. Food Chem. 44:1108-1110.

15. King, R. R., Lawrence, C. H., and Calhoun, L. A. 1992. Chemistry of phytotoxins associated with Streptomyces scabies, the causal organism of potato common scab. J. Agric. Food Chem. 40:834-837.

16. King, R. R., Lawrence, C. H., and Clark, M. C. 1989. Isolation and characterization of phytotoxins associated with Streptomyces scabies, the causal organism of potato common scab. J. Agric. Food Chem. 13:849-850.

17. King, R. R., Lawrence, C. H., and Clark, M. C. 1991. Correlation of phytotoxin production with pathogenicity of Streptomyces scabies isolates from scab infected potato tubers. Am. Potato J. 68:675-680.

18. Lawrence, C. H., Clark, M. C., and King, R. R. 1990. Induction of common scab symptoms in aseptically cultured potato tubers by the vivotoxin, thaxtomin. Phytopathology 80:606-608.

19. Leiner, R. H., Fry, B. A., Carling, D. E., and Loria, R. 1996. Probable involvement of thaxtomin A in pathogenicity of Streptomyces scabies on seedlings. Phytopathology 86:709-713.

20. Loria, R., Bukhalid, R. A., Creath, R. A., Leiner, R. H., Olivier, M., and Steffens, J. C. 1995. Differential production of thaxtomins by pathogenic Streptomyces species in vitro. Phytopathology 85:537-541.

21. Manulis, S., Shafrir, H., Epstein, E., Lichter, A., and Barash, I. 1994. Biosynthesis of indole-3-acetic acid via the indole-3-acetamide pathway in Streptomyces spp. Microbiology 140:1045-1050.

22. Matthews, D. E., and Durbin, R. D. 1994. Mechanistic aspects of tagetitoxin inhibition of RNA polymerase from Escherichia coli. Biochemistry 33:11987-11992.

23. McQueen, D. A. R., and Schottel, J. L. 1987. Purification and characterization of a novel extracellular esterase from pathogenic Streptomyces scabies that is inducible by zinc. J. Bacteriol. 169:1967-1971.

24. Meksuriyen, D., and Cordell, G. A. 1988. Biosynthesis of staurosporine, incorporation of tryptophan. J. Nat. Prod. (Lloydia) 51:893-899.

25. Mitchell, R. E. 1984. The relevance of non-host-specific toxins in the expression of virulence by pathogens. Annu. Rev. Phytopathol. 22:215-245.

26. Moore, R. A., Starratt, A. N., Mam, S.-W., Morris, V. L., and Cuppels, D. A. 1989. Identification of a chromosomal region required for biosynthesis of the phytotoxin coronatine by Pseudomonas syringae pv. tomato. Can. J. Microbiol. 35:910-917.

27. Panopoulos, N. J., and Peet, R. C. 1985. The molecular genetics of plant pathogenic bacteria and their plasmids. Annu. Rev. Phytopathol. 23:381-419.

28. Peet, R. C., Lindgren, P. B., Willis, D. K., and Panopoulos, N. J. 1986. Identification and cloning of genes involved in phaseolotoxin production by Pseudomonas syringae pv. phaseolicola. J. Bacteriol. 166:1096-1105.

29. Pridham, T. G., Anderson, P., Foley, C., Lindenfelser, L. A., Hessetine, C. W., and Benedict, R. G. 1956-1957. A selection of media for maintenance and taxonomic study of streptomycetes. Antibiot. Annu. 1956-1957:947-953.

30. Speedie, M. K., and Hartley, D. 1984. Demonstration of a metabolic grid at an early step in the streptonigrin biosynthetic pathway in Streptomyces flocculus. J. Antibiot. (Tokyo) 37:159-166.

31. Takemoto, J. Y. 1992. Bacterial phytotoxin syringomycin and its interaction with host membrane. Pages 247-260 in: Molecular Signals in PlantMicrobe Communications. D. P. Verma, ed. CRC Press, Boca Raton, FL.

32. Troost, T., and Katz, E. 1979. Phenoxazinone biosynthesis: Accumulation of a precursor, 4-methyl-3-hydrozyanthranilic acid, by mutants of Streptomyces parvulus. J. Gen. Microbiol. 111:121-132.

33. Turner, J. G., and Taha, R. R. 1984. Contribution of tabtoxin in the pathogenicity of Pseudomonas syringae pv. tabaci. Physiol. Plant Pathol. 25:55-69.

34. Vargha, G., Zs.-Nagy, V., Lustyik, G., and Szabo, G. 1986. Methionone requirement of sporulation in a Streptomyces fradiae mutant. J. Gen. Microbiol. 132:2931-2936. 